\title{
Dynamics of long-distance signaling via plant vascular tissues
}

\author{
Michitaka Notaguchi ${ }^{1,2 *}$ and Satoru Okamoto ${ }^{1,3 *}$ \\ 1 Graduate School of Science, Nagoya University, Nagoya, Japan, ${ }^{2}$ ERATO Higashiyama Live-Holonics Project, Nagoya, \\ Japan, ${ }^{3}$ Research Fellow of the Japan Society for the Promotion of Science, Tokyo, Japan
}

\section{OPEN ACCESS}

Edited by:

Masaru Fujimoto,

The University of Tokyo, Japan

Reviewed by:

Koh Aoki,

Osaka Prefecture University, Japan

Shinobu Satoh,

University of Tsukuba, Japan

*Correspondence:

Michitaka Notaguchi and

Satoru Okamoto,

Graduate School of Science, Nagoya

University, Furo-cho, Chikusa-ku,

Nagoya 464-8602, Japan

notaguchi.michitaka@b.mbox.nagoya-

u.ac.jp;

okamoto.satoru@j.mbox.nagoya-

u.ac.jp

Specialty section:

This article was submitted to Plant Physiology, a section of the journal Frontiers in Plant Science

Received: 31 January 2015 Accepted: 01 March 2015

Published: 18 March 2015

Citation:

Notaguchi M and Okamoto S (2015)

Dynamics of long-distance signaling

via plant vascular tissues.

Front. Plant Sci. 6:161.

doi: $10.3389 /$ fpls.2015.00161
Plant vascular systems are constructed by specific cell wall modifications through which cells are highly specialized to make conduits for water and nutrients. Xylem vessels are formed by thickened cell walls that remain after programmed cell death, and serve as water conduits from the root to the shoot. In contrast, phloem tissues consist of a complex of living cells, including sieve tube elements and their neighboring companion cells, and translocate photosynthetic assimilates from mature leaves to developing young tissues. Intensive studies on the content of vascular flow fluids have unveiled that plant vascular tissues transport various types of gene product, and the transport of some provides the molecular basis for the long-distance communications. Analysis of xylem sap has demonstrated the presence of proteins in the xylem transpiration stream. Recent studies have revealed that CLE and CEP peptides secreted in the roots are transported to above ground via the xylem in response to plant-microbe interaction and soil nitrogen starvation, respectively. Their leucine-rich repeat transmembrane receptors localized in the shoot phloem are required for relaying the signal from the shoot to the root. These findings well-fit to the current scenario of root-to-shoot-to-root feedback signaling, where peptide transport achieves the root-to-shoot signaling, the first half of the signaling process. Meanwhile, it is now well-evidenced that proteins and a range of RNAs are transported via the phloem translocation system, and some of those can exert their physiological functions at their destinations, including roots. Thus, plant vascular systems may serve not only as conduits for the translocation of essential substances but also as long-distance communication pathways that allow plants to adapt to changes in internal and external environments at the whole plant level.

Keywords: long-distance signaling, RNA transport, peptide transport, phloem transport, protein transport, systemic signaling, xylem transport

\section{Introduction}

Plant vascular tissues are formed through highly specialized cell wall modifications to achieve their roles as conduits of water and nutrients. The processes of cell differentiation in xylem and phloem tissues have been intensively studied, and many regulatory genes have been identified and characterized (only relatively new topics are introduced in this review). Through the functions

Abbreviations: CC, companion cell; CEP, C-terminally encoded peptide; CK, cytokinin; CLE, CLV3/ESR-related; CLE-RS2, CLE-root signal 2; CLV, CLAVATAV; CRA2, compact root architecture 2; FT, FLOWERING LOCUS T; IAA, indole-3-acetic acid; IPT, isopentenyltransferase; LRR-RK, leucine-rich repeat receptor kinase; PD, plasmodesmata; SE, sieve element; TE, tracheary element; XIP1, xylem intermixed with phloem1; XSP10, xylem sap protein 10. 
of such genetic components, xylem vessels, and phloem sieve tubes are formed running through the entire plant body. Such structures are well-designed to play their roles of conduits for water and nutrients.

Another facet of plant vascular tissues has been also described, that is their use as long-distance signaling pathways (Lucas et al., 2013). For multicellular organisms, communication at the entire body level is an essential task to coordinate behaviors within the organism as a singular living being. Whereas animals have evolved nervous systems to transmit information signal from one part of body to another, plants do not have a nervous system. Plants do use electrical signals to transmit information, for example, soon after wounding (Mousavi et al., 2013) or after salt stress treatment (Choi et al., 2014). However, electrical systems in plants appear not to be sufficient to provide the basis for expansive systemic responses. Alternatively, plants seem to use vascular tissues for long-distance communication. This review summarizes the potential signal agents transported via xylem and phloem, and especially focuses on gene-encoded macromolecules. Together, we discuss on the bi-directional flow of the information and the circuits used for signaling through these conduit tissues.

\section{Xylem Signaling}

Xylem consists of TEs, parenchyma cells, and fiber cells. These cells become differentiated from derivatives of the apical meristems (Evert, 2006), and dedicated studies have identified many factors involved in xylem cell differentiation and patterning (Schuetz et al., 2013; Kondo et al., 2014). TEs are formed as shells of cells that possess thickened secondary cell walls and lose their nuclei and cell contents through programmed cell death (Fukuda, 1996). Multiple TEs compose conduits, and continuous conduits connect various organs and tissues from the root to the shoot. Xylem vessels provide physical support for aerial organs and transport water and essential nutrients from the soil. In addition, xylem transports various molecules including long-distance signaling factors that mediate organ-to-organ communication.

Trans-zeatin type CKs have been mainly detected in xylem sap (Takei et al., 2001). Grafting experiments using a quadruple mutant of CK synthetic genes, ATP/ADP IPT 1;3;5; 7, indicated that a trans-zeatin type of CKs is transported from the roots to the shoots and regulate shoot growth (Matsumoto-Kitano et al., 2008). An ABC transporter, ABCG14, has been suggested to play a role in loading CKs to xylem (Ko et al., 2014; Zhang et al., 2014). ABCG14 is primary expressed in root vascular tissues, and the defect in ABCG14 resulted in an accumulation of CKs in roots. Strigolactones (SLs) control shoot branching as well as known as root-secreted signals for interactions with symbiotic fungi and parasitic weeds (Bouwmeester et al., 2003; Akiyama et al., 2005; Gomez-Roldan et al., 2008; Umehara et al., 2008). In inhibition of shoot branching, SLs and their precursor, carlactone, were proposed to be long-distance signaling factors. SLs have been detected in xylem sap (Kohlen et al., 2011), whereas grafting experiments using a series of mutants of SL synthetic enzymes and biochemical analyses on SL synthetic pathway suggested that carlactone is a root-to-shoot mobile signal (Booker et al., 2005; Seto and Yamaguchi, 2014; Seto et al., 2014). Although the major player in long-distance inhibition of shoot branching is still unknown, these findings describe that small phytohormones play essential roles in plant root-to-shoot coordination.

\section{Xylem Mobile Proteins}

In addition to phytohormones, macromolecules, such as proteins, were detected from xylem exudates in Biles and Abeles (1991) and Satoh et al. (1992). Since that time, many proteins have been identified in xylem sap of various plant species including Cucumis sativus, Brassica oleracea, Zea mays, and Glycine max (Sakuta et al., 1998; Masuda et al., 1999; Rep et al., 2002; Buhtz et al., 2004; Kehr et al., 2005; Djordjevic et al., 2007; Aki et al., 2008; Alvarez et al., 2008; Fernandez-Garcia et al., 2011; Ligat et al., 2011). Xylem sap is easy to collect from those large-sized plants with root pressure, and many proteins have been identified in the sap, including structural proteins of cell walls and defense-related proteins. Molecular genetic approach has been applied to XSP10 in tomato. XSP10 is a cysteinerich $10 \mathrm{kDa}$ secreted protein and displays structural similarity to lipid transfer protein (Rep et al., 2003). XSP10 is expressed in roots and lower stems. By using XSP10-silenced tomato, Krasikov et al. (2011) reported that XSP10 is involved in the susceptibility of tomato to a fungal vascular pathogen. Although using molecular genetics approaches on those non-model plants is not easy, functional analyses of proteins associated with xylem sap may reveal the roles of xylem in many aspects of plant life.

\section{Xylem Mobile Small Peptides}

As genomic information becomes available, many genes that encode small-secreted peptide have been found in various plant species. It is predicted that Arabidopsis genome contains more than 900 peptide genes (Matsubayashi, 2011). Intensive studies on some of these peptides and their receptors have revealed that a number of secreted peptides play an important role in relatively short-range cell-to-cell communication (Fletcher et al., 1999; Hirakawa et al., 2008; Ohyama et al., 2009; Lee et al., 2012). The CLV3/CLV1 ligand/receptor pair is a well-known cell-tocell signaling model, where its active form of CLV3 peptide belonging to the CLE family is perceived by CLV1 LRR-RK (Ohyama et al., 2009). CLV3 and CLV1 are expressed in adjacent cells in the shoot apex and control the activity of the shoot apical meristem in same genetic pathway (Clark et al., 1995, 1997; Fletcher et al., 1999). On the other hand, in xylem that is a kind of apoplast, whether small-secreted peptides exist and mediate organ-to-organ communication remained unknown. Recently, secreted oligopeptides belonging to the CLE peptide or the CEP family have been shown to be translocated from the roots to the shoots to act as long-distance signaling factors in systemic suppression of nodule formation or in nitrogen starvation response of root systems, respectively (Okamoto et al., 2013; Tabata et al., 2014; Figure 1A). We summarize recent findings related to those two secreted peptides below. 
Leguminous plants establish a symbiosis with soil bacteria, called rhizobia, and form nodules on their roots. Because excessive nodule formation is harmful to host plants, the plants control the number of nodules via a root-to-shoot-to-root longdistance feedback loop (Caetano-Anolles and Gresshoff, 1991). This regulatory loop is called autoregulation of nodulation, and two long-distance signals, namely, "root-derived signal (rootto-shoot)" and "shoot-derived inhibitor (shoot-to-root)" have been postulated. However, the entities of those long-distance signals have been unknown for more than two decades. As a strong candidate for the root-derived signal, CLE-RS2 oligopeptide was identified from a model legume Lotus japonicus. CLE$R S 2$ is expressed in roots and is highly up regulated by rhizobial inoculation (Okamoto et al., 2009). The active form of CLE-RS2 is a glycosylated 13-amino acid oligopeptide, and it strongly suppressed nodule formation. Importantly, biochemical analyses have revealed that CLE-RS2 glycopeptide was translocated from the root to the shoot via xylem, and that it directly bound HAR1 receptor that is a CLV1-homologous receptor and a shoot factor for the autoregulation of nodulation (Krusell et al., 2002; Nishimura et al., 2002; Okamoto et al., 2013). Homologs of CLE-RS2 and HAR1 were found in Medicago truncatula and soybean, suggesting that this signaling mechanism is common in legumes (Nishimura et al., 2002; Searle et al., 2003; Schnabel et al., 2005; Mortier et al., 2010, 2011; Lim et al., 2011; Reid et al., 2011).

Systemic signaling of CLE-RS2/HAR1 were implied in the studies on nitrate inhibition of nodulation, where CLE-RS2 was also strongly up regulated under high nitrate conditions that are known to abolish nodulation (Okamoto et al., 2009) and grafting experiments using a harl mutant showed that shootexpressed HAR1 is critical to nitrate inhibition of nodulation (Okamoto and Kawaguchi, 2015). Additionally, root overexpression of two types of CLE-RS2 homologs suppressed nodulation in systemic or local manner in soybean (Reid et al., 2011). Domainswapping experiments between them showed that not only CLE domain but also the external regions are important for the activity to suppress nodulation (Reid et al., 2013). This could reflect the difference of each CLE peptides in their activation or recognition by their receptors. In Arabidopsis, CLE6 overexpression in roots affected shoot morphology (Bidadi et al., 2014). Thus, it appears that CLE peptide-mediated long-distance signaling is not specific to legumes.

Another family of secreted peptides, CEPs, is involved in rootto-shoot signaling triggered by nitrogen starvation. CEP peptides were identified using an in silico approach on the Arabidopsis genome. Mature CEP1 peptide is a 15 aa oligopeptide that is derived from a conserved domain of the C-terminal region of precursor polypeptide (Ohyama et al., 2008). It is reported that some CEP genes responds to the nitrogen-poor conditions (Delay et al., 2013; Tabata et al., 2014). Tabata et al. (2014) identified CEP1 receptors in Arabidopsis, XIP1/CEPR1 and CEPR2, and found that a double mutant of CEPRs exhibited a pleiotropic phenotype relative to nitrogen starvation. Application of CEP1 peptides into roots resulted in up-regulation of NRT2.1, encoding a nitrate transporter, in a shoot CEPRs-dependent manner, and some CEP peptides have been detected in the xylem sap. It is proposed that plants employ several types of nitrogen-related systemic root-to-shoot-to-root signaling and coordinate root responses in heterogeneous nitrogen environments at the whole plant level (Ruffel et al., 2011). These results strongly suggest that CEP peptide functions as a nitrogen-demand root-to-shoot signal.

$C E P$ genes are widespread among seed plants (Roberts et al., 2013). In M. truncatula, some CEP genes were also induced by low nitrogen conditions. Overexpression of MtCEP1 resulted in the inhibition of lateral root formation and the enhancement of nodule formation (Imin et al., 2013). Additionally, a homolog of CEPR1 receptor gene, CRA2, was also characterized in $M$. truncatula. The cra2 mutants formed an increased number of lateral roots and a decreased number of nodules, the phenotype of which is opposite to $M t C E P 1$ overexpressing plants. Interestingly, grafting experiments showed that CRA2 functions using two different pathways. CRA2 inhibits lateral root development in a local manner, but enhances nodule formation in a systemic manner from the shoot. These findings raise the possibility that MtCEPs acts in both systemically and locally via CRA2 (Huault et al., 2014).

As shown here, the studies in recent years on the secreted oligopeptides provided new insight into organ-to-organ signaling mechanism through xylem. Furthermore, a number of undetermined mobile peptides have been identified through the analysis of xylem sap in soybean (Okamoto et al., unpublished data). In addition, many receptors have been found from the transcriptomic analyses of phloem tissues (e.g., Deeken et al., 2008). These imply general importance of secreted peptide transport via xylem on plant long-distance signaling.

\section{Phloem Signaling}

Phloem SE cells form a transport network for long-distance allocation of photosynthates and signaling molecules (Lucas et al., 2013). Mature SE cells are developed from undifferentiated future phloem cells, called protophloem SEs, through specialized autolysis processes accompanied by enucleation (Esau, 1950; Furuta et al., 2014). The protophloem cells are sequentially generated as a line in the meristematic tissues resulting in a network of phloem cells running through the entire body. Molecular genetics studies in Arabidopsis revealed that ALTERED PHLOEM DEVELOPMENT, a key transcription factor regulating phloem development, is expressed in the protophloem cells and promotes phloem development (Bonke et al., 2003). This phloem differentiation, accompanied by degradation of some organelles and enucleation, is achieved through the function of $N A C 45 / 86$ downstream genes, which target a family of genes, NAC45/86 DEPENDENT EXONUCLEASE-DOMAIN PROTEIN 1-4, encoding proteins with nuclease domains, essential for enucleation (Furuta et al., 2014). Thus, phloem tube systems are sequentially constructed through the processes of genetically controlled cell differentiation from adjacent region to the meristem and connecting to the differentiated leaves, stems, and roots.

Translocation of molecules into SEs can be achieved by two pathways; from apoplasmic to intracellular region, or cell-to-cell 
symplasmic transport via the specialized secondary PD interconnecting the SEs and neighboring CC (Oparka and Turgeon, 1999). At present, it is generally agreed that phloem flow is driven by a hydrostatic pressure gradient along the tube according to Münch's pressure-flow hypothesis, although this hypothesis has not yet been supported unequivocally (Knoblauch and Oparka, 2012). Considerable obstacles to the study of phloem cause difficulties in understanding of dynamics of living phloem tissues. While xylem sap can be easily collected as root pressure exudates, phloem sap has been collected from cut insect stylets (with a rate of several $\mu \mathrm{L} / \mathrm{h}$ ) or as exudates from incisions into stems, petioles, floral axes, or fruits with the use of chelating agents, e.g., EDTA to eliminate sieve tube blockage (Hoad, 1995). Phloem flow transports small molecules such as photosynthesized sugars, metabolites and phytohormones, as well as macromolecules such as proteins and a variety of RNA species. As shown below, a portion of these phloem-mobile molecules serve as information signals. Recent reviews describing phloem transport of each group of molecules are also available elsewhere (Kehr, 2006; Lough and Lucas, 2006; Kehr and Buhtz, 2008; Lucas et al., 2013).

\section{Phloem Mobile Phytohormones}

Analysis of phloem exudates has provided evidence for that phloem transports several phytohormones, including auxin, CKs, abscisic acid, and gibberellins (Hoad, 1995). Jasmonic acids, salicylic acids, and/or their derivatives are also proposed as components of the phloem sap in association with defense signaling (Vlot et al., 2008). IAA and other IAA derivatives have been identified from phloem sap. AUX1, a putative auxin influx carrier expressed in higher ordered vascular tissues, as well as the other members of the AUX1 gene family, facilitate the loading of IAA into vascular tissues and the transport of IAA from source leaves to sink tissues such as roots via the phloem (Marchant et al., 2002). iP-type CKs are main contents of leaf exudates, whereas tZ-type CKs are the major species in the xylem (Sakakibara, 2006). A biosynthesis gene, AtIPT3, and a purine permease gene, AtPUP2, are expressed in phloem tissues (Burkle et al., 2003; Miyawaki et al., 2004; Takei et al., 2004). The latter is involved in CK nucleobase uptake to retrieve it into the phloem. Thus, the transportation of auxins and CKs via the phloem appears to be a controlled process. Additionally, hormone concentrations in the phloem change in response to the environmental and developmental conditions (Hoad, 1995). Therefore, mobile hormones in phloem should have key roles in controlling the physiology of plants, although the precise nature of most of their roles and the underling mechanisms remain to be elucidated. Recently CKs were proposed as a shoot-derived inhibitor in nodulation (see the later section).

\section{Phloem Mobile Proteins and RNAs}

The phloem translocation stream contains hundreds of proteins and hundreds of transcripts, including mRNA, small RNA, and long non-coding RNA. In the last decade, their roles in longdistance signaling have been demonstrated. The importance of protein transport has been established unequivocally by a case of FT, a florigen. FT and its homolog proteins expressing in the leaves promote meristem outgrowth, such as flowering in the shoot apical meristems (Figure 1A) and the initiation of growth of dormant buds or secondary shoot primordia (Böhlenius et al., 2006; Hiraoka et al., 2013; Niwa et al., 2013) as well as the tuberization in the underground stolons (Navarro et al., 2011). Meanwhile, several types of RNA species have been thought as phloem-mobile (Kehr and Buhtz, 2008), and the most agreed phenomenon involving RNA transport is siRNA triggering systemic silencing which is the basis for systemic acquired resistance (Bologna and Voinnet, 2014).

The discovery of FT protein transport, first as a florigenic signal, was led by the studies on photoperiodic flowering initiated early in the 19th century (Lang, 1965). Physiological experiments have revealed plant "phototropism" (Garner and Allard, 1920) and demonstrated the presence of hormone-like systemic signals generated in leaves under favorable photoperiodic conditions (Chailakhyan, 1937). Genetic studies on flowering have successfully identified a number of locus and/or genes related to flowering especially in pea, rice and Arabidopsis (Rédei, 1975; Koornneef et al., 1998; Yano et al., 2001; Weller et al., 2009). Subsequent characterization of these genes has narrowed down the position of the florigenic signal in the genetic cascades, between FT and FD genes (Abe et al., 2005; Wigge et al., 2005). Finally, the current conclusion that long-distance transport of FT protein, as a florigen, via phloem is the molecular basis for the promotion of flowering by photoperiodic control was agreed through the studies conducted by several research groups (Corbesier et al., 2007; Jaeger and Wigge, 2007; Lin et al., 2007; Mathieu et al., 2007; Tamaki et al., 2007; Notaguchi et al., 2008). An important role of FT, or its homologs, as it relates to flowering has been described in many plant species. Additionally, in chrysanthemum, CsAFT, a PEBP family gene which belongs to a different group from the FT group, is also generated in leaves and then moved to the apex to suppress flowering, which may be an antiflorigen, another proposed systemic signal which controls flowering (Higuchi et al., 2013). The transport mechanisms of FT or its homologs are as yet largely unknown, except for a clue from an ER membrane localized exporter, FT-INTERACTING PROTEIN 1, which is involved in protein loading of FT from the CC into the SE tube system (Liu et al., 2012). The existence of regulatory systems in long-distance FT transport has been also implied from the fact that amino acid substitutions of FT protein caused a defect only in its mobility, but not in activity that promotes flowering (Yoo et al., 2013). Near the shoot apical meristems, FT-GFP protein was detected in the provasculature at the apex and at the base of the shoot apical meristem, but this pattern was not observed in very young seedlings (Corbesier et al., 2007). These observations further support the presence of regulatory systems for FT protein movement.

Phloem exudates contain a number of proteins for the protection of functional phloem tubes. For an example, major structural phloem proteins encoded by SE occlusion gene family have roles in wound sealing of SEs to avoid nutrient loss (Ernst et al., 2012; Jekat et al., 2013). The analyses of phloem exudates also have identified a large quantity of proteins that are functionally related to defense response, such as proteinase inhibitors, lectins, and other proteins induced by wounding or insect feeding. These 
proteins disrupt feeding as well as digestion of phloem contents and includes some toxic proteins (Kehr, 2006). However, the functions of many of phloem proteins have yet to be elucidated. While the presence of a type of passive transport into SEs has been depicted by diffusion of GFP fused-proteins (Stadler et al., 2005), active transport may also occur because the phloem protein population includes proteins larger than $100 \mathrm{kDa}$ which is in excess of the PD size exclusion limits and such protein fractions have ability to increase size exclusion limits (Balachandran et al., 1997). Why plants deliver only a part of their proteins is an important question to be answered to understand the function of the phloem translocation stream as well as plant systemic signaling.

Endogenous cellular RNAs are known to be transported systemically; small non-coding RNAs, such as siRNA and miRNA, and mRNAs (Kehr and Buhtz, 2008). Among these, the function of siRNA has been most well-established. The mobility of siRNA was clearly explained by grafting experiments with multiple dicer mutants as recipients in which siRNA production does not occur. siRNA movement triggers post-transcriptional gene silencing and also transcriptional gene silencing, which is crucial for the achievement of systemic acquired resistance to pathogens and viruses in plants (Dunoyer et al., 2010; Molnar et al., 2010). miRNA movement via phloem is also supported by several evidences (Marín-González and Suárez-López, 2012). miR399 has been proposed as a mobile signal in response to phosphate starved conditions (Lin et al., 2008; Pant et al., 2008). miR395 has been identified using miRNA processing mutant hen1-1 under sulfate starved conditions (Buhtz et al., 2010). The mobility of the miR172 and miR156 regulating phase transitions such as flowering and tuberization have also been demonstrated (Martin et al., 2009; Kasai et al., 2010; Bhogale et al., 2014). Non-coding RNAs longer than si/miRNAs, ranging from 30 to 90 bases, were also found from pumpkin phloem exudates and, in the in vitro tests, they showed activities that inhibit protein translation (Zhang et al., 2009). Thus, non-coding RNAs regulate their target expression levels in their target tissues in their own manners.

mRNA transport has been also well-evidenced by grafting experiments (Notaguchi, 2015). Although the functions of mRNAs have been not clarified yet, their effect of several mRNA species on development has been observed; a dominant form of a KNOX mRNA, named $M e$, can result in altered leaf morphology (Kim et al., 2001), a dominant form of GAI mRNA resulted in modified leaf and fruit shapes (Haywood et al., 2005), a BEL1-like mRNA affected the tuberization (Banerjee et al., 2006), and dominant forms of two $A u x / I A A$ mRNAs affected the lateral root formation (Notaguchi et al., 2012). In addition, many of phloem mobile mRNAs were identified in Nicotiana benthamiana/Arabidopsis hetero-grafting experiments, in which the derivatives of the Arabidopsis donor mRNAs were undoubtedly identified from recipient $N$. benthamiana scions by differences of their genome sequence information (Notaguchi et al., 2015). Although the transport mechanisms are still largely unknown, a few studies have provided information on RNA-binding proteins for each of small RNA and mRNA (Xoconostle-Cázares et al., 1999; Yoo et al., 2004; Ham et al., 2009) as well as the importance of 3D RNA structure in viral RNA movement (Takeda et al., 2011). Additionally, no detectable RNase activity has been observed in the phloem implying that RNA transport has important roles in plant physiology (Sasaki et al., 1998; Doering-Saad et al., 2002). However, direct evidence for the biological relevance of long-distance transport of mRNA is still missing.

These findings collectively suggested that the phloem translocation system is highly specialized for systemic signaling where a range of molecules are delivered as signal agents. Currently, physiological and developmental roles of only a few molecules have been characterized or identified. Future challenges are to investigate their roles of remains and to reveal their aspects of how each molecular species is used for systemic signaling.

\section{A Link of Xylem and Phloem Pathways}

The necessity of long-distance signaling between separated organs, such as root-to-shoot, shoot-to-root, shoot-to-shoot and root-to-root, has been proposed through the observations of systemic responses to surrounding environmental conditions. For instance, plants respond to heterogeneous soil conditions of the availability of mineral macro- and micronutrients or local biotic stress such as insect attack, in which vascular tissues have been thought to be a pathway for the underlying long-distance signaling (Giehl et al., 2009; Liu et al., 2009; Soler et al., 2013). Xylem sap flow is directed from the roots to the shoot driven by water loss during transpiration and photosynthesis. In contrast, phloem sap flow is directed from the source mature leaves, where photosynthesis reaction is actively preceded with their large surfaces, to sink organs such as young developing meristems in the shoots and the roots. Therefore, translocations such as "root-to-shoot" and "shoot-to-root and shoot-to-shoot" can be simply achieved by the xylem and the phloem pathways, respectively.

On the other hand, "root-to-root" signaling, where signals are emitted from a part of roots and transmitted to another part of roots, could be partially explained by $\mathrm{Ca}^{2+}$ wave ranging in a part of roots (Choi et al., 2014); however, more generally, it appears to be achieved through the both xylem and phloem pathways, which has a "root-to-shoot-to-root" loop. This signaling circuit was more clearly established by recent discoveries of xylem mobile peptide signals as described in a previous section. The fact that receptors of xylem-mobile peptides are expressed in the phloem highlights a functional link between xylem and phloem signaling pathways. Analyses of GUS reporter lines for the receptors indicated that HAR1, a CLE-RS receptor, is preferentially expressed in the phloem (Nontachaiyapoom et al., 2007) and XIP1/CEPR1, a CEP1 receptor, is specifically expressed in the phloem (Bryan et al., 2012). These findings suggest that the phloem is the site where the root-derived peptides are converted to another secondary signal, and that such secondary messengers can be transported on the phloem sap flow toward "shoot-to-root." In fact, in the 


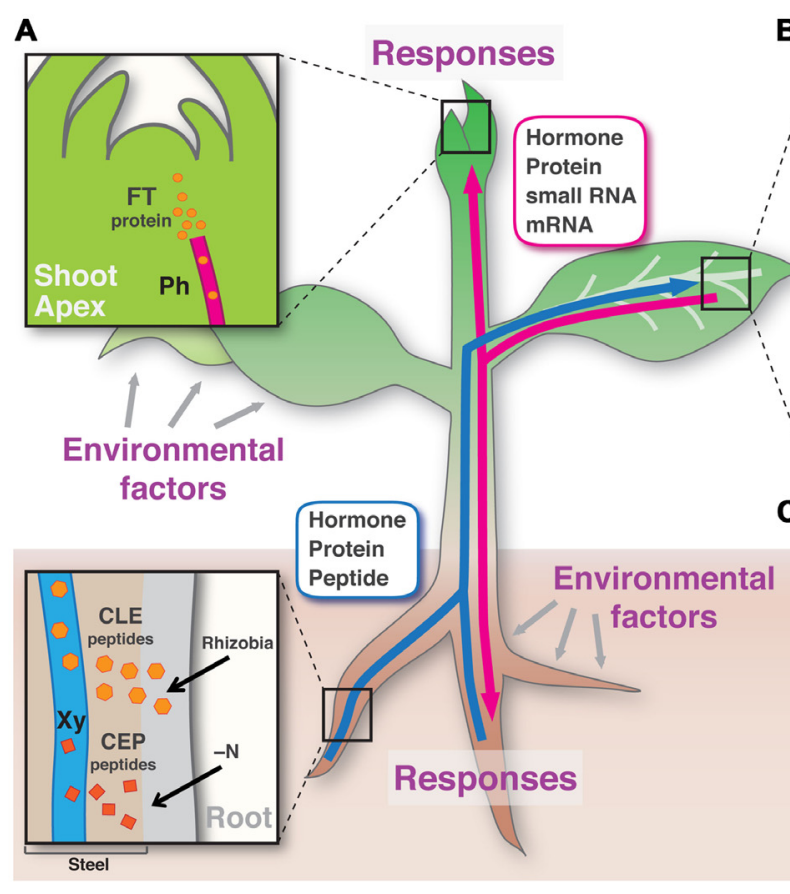

FIGURE 1|A model of long-distance signaling via plant vascular tissues. (A) Potential signal molecules of the xylem (blue) and the phloem (red) translocation pathways. Insets show xylem loading and phloem unloading of signal molecules in the sink tissues. (B) Signal
B

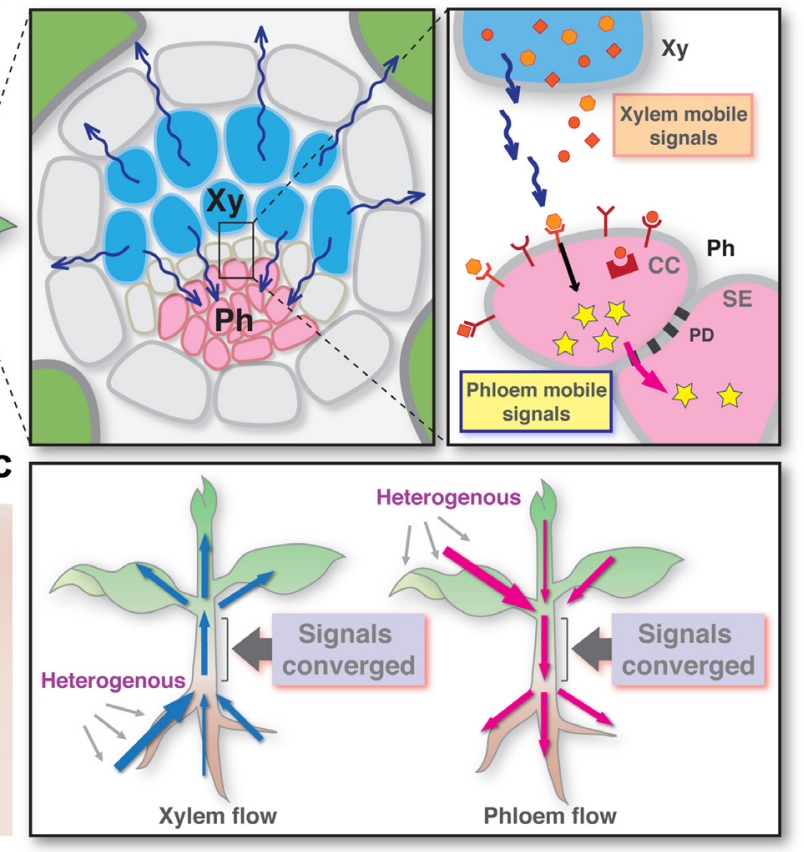

CLE-RS/HAR1 cascade, CKs has been proposed as the shootto-root signals generated in the phloem to control nodulation. In the presence of CLE-RS peptides, HAR1 receptor promotes the production of shoot CKs through the up-regulation of a CK synthase, LjIPT3, in the phloem tissues; thus, the generated CKs could exert their activities to inhibit nodulation (Sasaki et al., 2014). In addition to nodulation control, the shootderived CKs could trigger the other physiological changes in the roots. Alternatively, other unrevealed secondary signal, if present, may explain this signaling specificity. Another important future question is the temporal aspects of shoot-derived CKs signaling to understand the mechanism to control the balanced symbiosis. Nodulation is a specialized phenomenon evolved in legumes that allows nitrogen fixation through a symbiosis with rhizobia, but the CKs biosynthesis is also strongly affected by nitrogen sources in plants other than legumes (Sakakibara, 2006). Hence, the CEP peptide pathway triggered by nitrogen starvation could also link with CKs cascade in downstream signaling.

These recent findings shed light on an advanced concept that the xylem and the phloem pathways develop a long-distance root-to-shoot and then shoot-to-root signaling feedback circuit in plants. In this scenario, signal molecules are transmitted across long-distances to response the soil environments via the vascular tissues with the following sequential processes. First, the information signaling molecules, generated in somewhere or in all parts of the branched root system, move shoot-ward via the relay from the xylem to the phloem in the leaf vein. (C) Signal convergence by running through a stem region in each of xylem and phloem pathways. Xy, xylem; Ph, phloem; CC, companion cell; SE, sieve element; PD, plasmodesmata. xylem. Second, the signals run through a stem region between branched root and branched shoot and disperse to each of the mature leaves, possibly to the minor veins (Figure 1A). Third, the signal molecules are translocated from the xylem to the phloem and perceived by the receptors located on the phloem cells. In this process, the information is converted to the secondary signal inside of the phloem cells (Figure 1B). Fourth, the intracellular signal molecules travel on the phloem sap flow, including shoot-to-root translocation. Thus, finally the information signals generated in a part of root system can transmit to another part of the root. In each of these shoot- and rootward translocation flows, all signaling molecules generated in branches of organs in response to heterologous environmental factors should be physically converged by running through a stem region (the bases of shoot and root), which ought to be the sole pathway (Figure 1C). This convergence might be the way to measure the entire signal level by averaging of the intensities of the signals generated in local and to make decisions how to respond or how much plants respond. Dosage control is a possible and quite likely mechanism that can be used to measure the level of signals. These points need to be addressed in the future studies. As described here, although plants do not have a circulatory system connecting the entire body as observed in animals, bi-directional signaling can be achieved by linking the xylem and phloem translocation pathways, and this may represent an elaborate signaling mechanism in plants. 


\section{Concluding Remarks}

In our current view, numerous mobile molecules that include secreted peptides in the xylem and proteins and RNA species in the phloem could have roles as specific information signals. In contrast to animal systems, where nervous systems and vascular tissues contribute to signaling and nutrient delivery (a sort of signaling as well), respectively, plant vascular systems serve as conduits for water and nutrients as well as long-distance signaling pathways which includes root-to-shoot signaling via the xylem, shoot-to-sink (such as the roots and young growing tissues in the shoots) signaling via the phloem, and a root-to-shoot-toroot circuit via the xylem as the first half and the phloem as the second half. Importantly, to reach their final destinations in each long-distance translocation pathway, short-distance transport after unloading usually at the terminus of vascular tissues is also necessary. The roles of most xylem peptides and phloem proteins and RNAs in plant development and physiology are still largely unknown. Additionally, long-distance transport has

\section{References}

Abe, M., Kobayashi, Y., Yamamoto, S., Daimon, Y., Yamaguchi, A., Ikeda, Y., et al. (2005). FD, a bZIP protein mediating signals from the floral pathway integrator FT at the shoot apex. Science 309, 1052-1056. doi: 10.1126/science.1115983

Aki, T., Shigyo, M., Nakano, R., Yoneyama, T., and Yanagisawa, S. (2008). Nano scale proteomics revealed the presence of regulatory proteins including three FT-Like proteins in phloem and xylem saps from rice. Plant Cell Physiol. 49, 767-790. doi: 10.1093/pcp/pcn049

Akiyama, K., Matsuzaki, K., and Hayashi, H. (2005). Plant sesquiterpenes induce hyphal branching in arbuscular mycorrhizal fungi. Nature 435, 824-827. doi: 10.1038/nature03608

Alvarez, S., Marsh, E. L., Schroeder, S. G., and Schachtman, D. P. (2008). Metabolomic and proteomic changes in the xylem sap of maize under drought. Plant Cell Environ. 31, 325-340. doi: 10.1111/j.1365-3040.2007. 01770.x

Balachandran, S., Xiang, Y., Schobert, C., Thompson, G. A., and Lucas, W. J. (1997). Phloem sap proteins from Cucurbita maxima and Ricinus communis have the capacity to traffic cell to cell through plasmodesmata. Proc. Natl. Acad. Sci. U.S.A. 94, 14150-14155. doi: 10.1073/pnas.94.25.14150

Banerjee, A. K., Chatterjee, M., Yu, Y., Suh, S. G., Miller, W. A., and Hannapel, D. J. (2006). Dynamics of a mobile RNA of potato involved in a long-distance signaling pathway. Plant Cell 18, 3443-3457. doi: 10.1105/tpc.106.042473

Bhogale, S., Mahajan, A. S., Natarajan, B., Rajabhoj, M., Thulasiram, H. V., and Banerjee, A. K. (2014). MicroRNA156: a potential graft-transmissible microRNA that modulates plant architecture and tuberization in Solanum tuberosum ssp. andigena. Plant Physiol. 164, 1011-1027. doi: 10.1104/pp.113.230714

Bidadi, H., Matsuoka, K., Sage-Ono, K., Fukushima, J., Pitaksaringkarn, W., Asahina, M., et al. (2014). CLE6 expression recovers gibberellin deficiency to promote shoot growth in Arabidopsis. Plant J. 78, 241-252. doi: $10.1111 /$ tpj.12475

Biles, C. L., and Abeles, F. B. (1991). Xylem sap proteins. Plant Physiol. 96, 597-601. doi: 10.1104/pp.96.2.597

Böhlenius, H., Huang, T., Charbonnel-Campaa, L., Brunner, A. M., Jansson, S., Strauss, S. H., et al. (2006). CO/FT regulatory module controls timing of flowering and seasonal growth cessation in trees. Science 312, 1040-1043. doi: $10.1126 /$ science. 1126038

Bologna, N. G., and Voinnet, O. (2014). The diversity, biogenesis, and activities of endogenous silencing small RNAs in Arabidopsis. Annu. Rev. Plant Biol. 65, 473-503. doi: 10.1146/annurev-arplant-050213-35728.

Bonke, M., Thitamadee, S., Mahonen, A. P., Hauser, M. T., and Helariutta, Y. (2003). APL regulates vascular tissue identity in Arabidopsis. Nature 426, 181-186. doi: $10.1038 /$ nature 02100 been suggested for the other molecules such as a lipid, glycerol-3phosphate, that is used for systemic immunity (Chun et al., 2002; Chanda et al., 2011); however, their delivered pathway has yet to be elucidated. Reactive oxygen species may also serve as potential systemic signals (e.g., Miller et al., 2009). Thus, further studies are required to elucidate the functions and nature of vascular mobile molecules, together with the transport mechanisms involved in their movement.

\section{Acknowledgments}

The authors acknowledge the topic editors for giving us this opportunity to share our understanding of long-distance signaling in plants through vasculature tissues. The writing this review and conducting this research were supported by Grants-in-Aid for Scientific Research (No. 25650095 to MN) and JSPS Research Fellows from the Japan Society for the Promotion of Science (No. A2406127 to SO).

Booker, J., Sieberer, T., Wright, W., Williamson, L., Willett, B., Stirnberg, P., et al. (2005). MAX1 encodes a cytochrome P450 family member that acts downstream of MAX3/4 to produce a carotenoid-derived branch-inhibiting hormone. Dev. Cell 8, 443-449. doi: 10.1016/j.devcel.2005. 01.009

Bouwmeester, H. J., Matusova, R., Zhongkui, S., and Beale, M. H. (2003). Secondary metabolite signalling in host-parasitic plant interactions. Curr. Opin. Plant Biol. 4, 358-364. doi: 10.1016/S1369-5266(03)00065-7

Bryan, A. C., Obaidi, A., Wierzba, M., and Tax, F. E. (2012). XYLEM INTERMIXED WITH PHLOEM1, a leucine-rich repeat receptor-like kinase required for stem growth and vascular development in Arabidopsis thaliana. Planta 235, 111-122. doi: 10.1007/s00425-011-1489-6

Buhtz, A., Kolasa, A., Arlt, K., Walz, C., and Kehr, J. (2004). Xylem sap protein composition is conserved among different plant species. Planta 219, 610-618. doi: 10.1007/s00425-004-1259-9

Buhtz, A., Pieritz, J., Springer, F., and Kehr, J. (2010). Phloem small RNAs, nutrient stress responses, and systemic mobility. BMC Plant Biol. 10:64. doi: 10.1186/1471-2229-10-64

Burkle, L., Cedzich, A., Dopke, C., Stransky, H., Okumoto, S., Gillissen, B., et al. (2003). Transport of cytokinins mediated by purine transporters of the PUP family expressed in phloem, hydathodes, and pollen of Arabidopsis. Plant J. 34, 13-26. doi: 10.1046/j.1365-313X.2003.01700.x

Caetano-Anolles, G., and Gresshoff, P. M. (1991). Plant genetic control of nodulation. Annu. Rev. Microbiol. 45, 345-382. doi: 10.1146/annurev.mi.45.100191.002021

Chailakhyan, M. K. (1937). Concerning the hormonal nature of plant development processes. Dokl. Akad. Nauk SSSR 16, 227-230.

Chanda, B., Xia, Y., Mandal, M. K., Yu, K., Sekine, K. T., Gao, Q. M., et al. (2011). Glycerol-3-phosphate is a critical mobile inducer of systemic immunity in plants. Nat. Genet. 43, 421-427. doi: 10.1038/ng.798

Choi, W. G., Toyota, M., Kim, S. H., Hilleary, R., and Gilroy, S. (2014). Salt stress-induced $\mathrm{Ca} 2+$ waves are associated with rapid, long-distance root-toshoot signaling in plants. Proc. Natl. Acad. Sci. U.S.A. 111, 6497-6502. doi: 10.1073/pnas.1319955111

Chun, H. J., Zheng, L., Ahmad, M., Wang, J., Speirs, C. K., Siegel, R. M., et al. (2002). Pleiotropic defects in lymphocyte activation caused by caspase8 mutations lead to human immunodeficiency. Nature 419, 395-399. doi: 10.1038/nature01063

Clark, S. E., Running, M. P., and Meyerowitz, E. M. (1995). CLAVATA3 is a specific regulator of shoot and floral meristem development affecting the same processes as CLAVATA1. Development 121, 2057-2067.

Clark, S. E., Williams, R. W., and Meyerowitz, E. M. (1997). The CLAVATA1 gene encodes a putative receptor kinase that controls shoot and floral meristem size in Arabidopsis. Cell 89, 575-585. doi: 10.1016/S0092-8674(00)80239-1 
Corbesier, L., Vincent, C., Jang, S., Fornara, F., Fan, Q., Searle, I., et al. (2007). FT protein movement contributes to long-distance signaling in floral induction of Arabidopsis. Science 316, 1030-1033. doi: 10.1126/science. 1141752

Deeken, R., Ache, P., Kajahn, I., Klinkenberg, J., Bringmann, G., and Hedrich, R. (2008). Identification of Arabidopsis thaliana phloem RNAs provides a search criterion for phloem-based transcripts hidden in complex datasets of microarray experiments. Plant J. 55, 746-759. doi: 10.1111/j.1365-313X.2008. 03555.x

Delay, C., Imin, N., and Djordjevic, M. A. (2013). CEP genes regulate root and shoot development in response to environmental cues and are specific to seed plants. J. Exp. Bot. 64, 5383-5394. doi: 10.1093/jxb/ert332

Djordjevic, M. A., Oakes, M., Li, D. X., Hwang, C. H., Hocart, C. H., and Gresshoff, P. M. (2007). The Glycine max xylem sap and apoplast proteome. J. Proteome Res. 6, 3771-3779. doi: 10.1021/pr0606833

Doering-Saad, C., Newbury, H. J., Bale, J. S., and Pritchard, J. (2002). Use of aphid stylectomy and RT-PCR for the detection of transporter mRNAs in sieve elements. J. Exp. Bot. 53, 631-637. doi: 10.1093/jexbot/53.369.631

Dunoyer, P., Schott, G., Himber, C., Meyer, D., Takeda, A., Carrington, J. C., et al. (2010). Small RNA duplexes function as mobile silencing signals between plant cells. Science 328, 912-916. doi: 10.1126/science. 1185880

Ernst, A. M., Jekat, S. B., Zielonka, S., Müller, B., Neumann, U., Rüping, B., et al. (2012). Sieve element occlusion (SEO) genes encode structural phloem proteins involved in wound sealing of the phloem. Proc. Natl. Acad. Sci. U.S.A. 109, E1980-E1989. doi: 10.1073/pnas.1202999109

Esau, K. (1950). Development and structure of the phloem tissue. II. Bot. Rev. 16, 67-114. doi: 10.1007/BF02919553

Evert, R. F. (2006). Esau's Plant Anatomy: Meristemos, Cell and Tissues of the Plant body: Their Structure, Function, and Development. New Jersey: WileyInterscience. doi: 10.1002/0470047380

Fernandez-Garcia, N., Hernandez, M., Casado-Vela, J., Bru, R., Elortza, F., Hedden, P., et al. (2011). Changes to the proteome and targeted metabolites of xylem sap in Brassica oleracea in response to salt stress. Plant Cell Environ. 34, 821-836. doi: $10.1111 / j .1365-3040.2011 .02285 . x$

Fletcher, J. C., Brand, U., Running, M. P., Simon, R., and Meyerowitz, E. M. (1999). Signaling of cell fate decisions by CLAVATA3 in Arabidopsis shoot meristems. Science 283, 1911-1914. doi: 10.1126/science.283.5409.1911

Fukuda, H. (1996). XYLOGENESIS: INITIATION, PROGRESSION, AND CELL DEATH. Annu. Rev. Plant Physiol. Plant Mol. Biol. 47, 299-325. doi: 10.1146/annurev.arplant.47.1.299

Furuta, K. M., Yadav, S. R., Lehesranta, S., Belevich, I., Miyashima, S., Heo, J. O., et al. (2014). Plant development. Arabidopsis NAC45/86 direct sieve element morphogenesis culminating in enucleation. Science 345, 933-937. doi: 10.1126/science. 1253736

Garner, W. W., and Allard, H. A. (1920). Effect of the relative length of day and night and other factors of the environment on growth and reproduction in plants. J. Agric. Res. 18, 553-606.

Giehl, R. F., Meda, A. R., and Von Wiren, N. (2009). Moving up, down, and everywhere: signaling of micronutrients in plants. Curr. Opin. Plant Biol. 12, 320-327. doi: 10.1016/j.pbi.2009.04.006

Gomez-Roldan, V., Fermas, S., Brewer, P. B., Puech-Pages, V., Dun, E. A., Pillot, J. P., et al. (2008). Strigolactone inhibition of shoot branching. Nature 455, 189-194. doi: 10.1038/nature 07271

Ham, B. K., Brandom, J. L., Xoconostle-Cázares, B., Ringgold, V., Lough, T. J., and Lucas, W. J. (2009). A polypyrimidine tract binding protein, pumpkin RBP50, forms the basis of a phloem-mobile ribonucleoprotein complex. Plant Cell 21, 197-215. doi: 10.1105/tpc.108.061317

Haywood, V., Yu, T. S., Huang, N. C., and Lucas, W. J. (2005). Phloem longdistance trafficking of GIBBERELLIC ACID-INSENSITIVE RNA regulates leaf development. Plant J. 42, 49-68. doi: 10.1111/j.1365-313X.2005.02351.x

Higuchi, Y., Narumi, T., Oda, A., Nakano, Y., Sumitomo, K., Fukai, S., et al. (2013). The gated induction system of a systemic floral inhibitor, antiflorigen, determines obligate short-day flowering in chrysanthemums. Proc. Natl. Acad. Sci. U.S.A. 110, 17137-17142. doi: 10.1073/pnas.1307617110

Hirakawa, Y., Shinohara, H., Kondo, Y., Inoue, A., Nakanomyo, I., Ogawa, M., et al. (2008). Non-cell-autonomous control of vascular stem cell fate by a CLE peptide/receptor system. Proc. Natl. Acad. Sci. U.S.A. 105, 15208-15213. doi: 10.1073/pnas.0808444105
Hiraoka, K., Yamaguchi, A., Abe, M., and Araki, T. (2013). The florigen genes FT and TSF modulate lateral shoot outgrowth in Arabidopsis thaliana. Plant Cell Physiol. 54, 352-368. doi: 10.1093/pcp/pcs168

Hoad, G. V. (1995). Transport of hormones in the phloem of higher plants. Plant Growth Regul. 16, 173-182. doi: 10.1007/BF00029538

Huault, E., Laffont, C., Wen, J., Mysore, K. S., Ratet, P., Duc, G., et al. (2014). Local and systemic regulation of plant root system architecture and symbiotic nodulation by a receptor-like kinase. PLoS Genet. 10:e1004891. doi: 10.1371/journal.pgen.1004891

Imin, N., Mohd-Radzman, N. A., Ogilvie, H. A., and Djordjevic, M. A. (2013). The peptide-encoding CEP1 gene modulates lateral root and nodule numbers in Medicago truncatula. J. Exp. Bot. 64, 5395-5409. doi: 10.1093/jxb/ert369

Jaeger, K. E., and Wigge, P. A. (2007). FT protein acts as a long-range signal in Arabidopsis. Curr. Biol. 17, 1050-1054. doi: 10.1016/j.cub.2007.05.008

Jekat, S. B., Ernst, A. M., Von Bohl, A., Zielonka, S., Twyman, R. M., Noll, G. A., et al. (2013). P-proteins in Arabidopsis are heteromeric structures involved in rapid sieve tube sealing. Front. Plant Sci. 4:225. doi: 10.3389/fpls.2013.00225

Kasai, A., Kanehira, A., and Harada, T. (2010). miR172 can move long distances in Nicotiana benthamiana. Open Plant Sci. J. 4, 1-6. doi: $10.2174 / 1874294701004010001$

Kehr, J. (2006). Phloem sap proteins: their identities and potential roles in the interaction between plants and phloem-feeding insects. J. Exp. Bot. 57, 767-774. doi: $10.1093 / \mathrm{jxb} / \mathrm{erj} 087$

Kehr, J., and Buhtz, A. (2008). Long distance transport and movement of RNA through the phloem. J. Exp. Bot. 59, 85-92. doi: 10.1093/jxb/erm176

Kehr, J., Buhtz, A., and Giavalisco, P. (2005). Analysis of xylem sap proteins from Brassica napus. BMC Plant Biol 5:11. doi: 10.1186/1471-2229-5-11

Kim, M., Canio, W., Kessler, S., and Sinha, N. (2001). Developmental changes due to long-distance movement of a homeobox fusion transcript in tomato. Science 293, 287-289. doi: 10.1126/science. 1059805

Knoblauch, M., and Oparka, K. (2012). The structure of the phloem-still more questions than answers. Plant J. 70, 147-156. doi: 10.1111/j.1365313X.2012.04931.x

Ko, D., Kang, J., Kiba, T., Park, J., Kojima, M., Do, J., et al. (2014). Arabidopsis ABCG14 is essential for the root-to-shoot translocation of cytokinin. Proc. Natl. Acad. Sci. U.S.A. 111, 7150-7155. doi: 10.1073/pnas.1321519111

Kohlen, W., Charnikhova, T., Liu, Q., Bours, R., Domagalska, M. A., Beguerie, S., et al. (2011). Strigolactones are transported through the xylem and play a key role in shoot architectural response to phosphate deficiency in nonarbuscular mycorrhizal host Arabidopsis. Plant Physiol. 155, 974-987. doi: $10.1104 /$ pp. 110.164640

Kondo, Y., Tamaki, T., and Fukuda, H. (2014). Regulation of xylem cell fate. Front. Plant Sci. 5:315. doi: 10.3389/fpls.2014.00315

Koornneef, M., Alonso-Blanco, C., Blankestijn-De Vries, H., Hanhart, C. J., and Peeters, A. J. (1998). Genetic interactions among late-flowering mutants of Arabidopsis. Genetics 148, 885-892.

Krasikov, V., Dekker, H. L., Rep, M., and Takken, F. L. (2011). The tomato xylem sap protein XSP10 is required for full susceptibility to Fusarium wilt disease. J. Exp. Bot. 62, 963-973. doi: 10.1093/jxb/erq327

Krusell, L., Madsen, L. H., Sato, S., Aubert, G., Genua, A., Szczyglowski, K., et al. (2002). Shoot control of root development and nodulation is mediated by a receptor-like kinase. Nature 420, 422-426. doi: 10.1038/nature01207

Lang, A. (1965). Physiology of Flower Initiation. Berlin: Springer Verlag.

Lee, J. S., Kuroha, T., Hnilova, M., Khatayevich, D., Kanaoka, M. M., Mcabee, J. M., et al. (2012). Direct interaction of ligand-receptor pairs specifying stomatal patterning. Genes Dev. 26, 126-136. doi: 10.1101/gad.179895.111

Ligat, L., Lauber, E., Albenne, C., San Clemente, H., Valot, B., Zivy, M., et al. (2011). Analysis of the xylem sap proteome of Brassica oleracea reveals a high content in secreted proteins. Proteomics 11, 1798-1813. doi: 10.1002/pmic.201000781

Lim, C. W., Lee, Y. W., and Hwang, C. H. (2011). Soybean nodule-enhanced CLE peptides in roots act as signals in GmNARK-mediated nodulation suppression. Plant Cell Physiol. 52, 1613-1627. doi: 10.1093/pcp/pcr091

Lin, M. K., Belanger, H., Lee, Y. J., Varkonyi-Gasic, E., Taoka, K., Miura, E., et al. (2007). FLOWERING LOCUS T protein may act as the long-distance florigenic signal in the cucurbits. Plant Cell 19, 1488-1506. doi: 10.1105/tpc.107.051920

Lin, S. I., Chiang, S. F., Lin, W. Y., Chen, J. W., Tseng, C. Y., Wu, P. C., et al. (2008). Regulatory network of microRNA399 and PHO2 by systemic signaling. Plant Physiol. 147, 732-746. doi: 10.1104/pp.108.116269 
Liu, L., Liu, C., Hou, X., Xi, W., Shen, L., Tao, Z., et al. (2012). FTIP1 is an essential regulator required for florigen transport. PLoS Biol. 10:e1001313. doi: 10.1371/journal.pbio.1001313

Liu, T. Y., Chang, C. Y., and Chiou, T. J. (2009). The long-distance signaling of mineral macronutrients. Curr. Opin. Plant Biol. 12, 312-319. doi: 10.1016/j.pbi.2009.04.004

Lough, T. J., and Lucas, W. J. (2006). Integrative plant biology: role of phloem longdistance macromolecular trafficking. Annu. Rev. Plant Biol. 57, 203-232. doi: 10.1146/annurev.arplant.56.032604.144145

Lucas, W. J., Groover, A., Lichtenberger, R., Furuta, K., Yadav, S. R., Helariutta, Y., et al. (2013). The plant vascular system: evolution, development and functions. J. Integr. Plant Biol. 55, 294-388. doi: 10.1111/jipb.12041

Marchant, A., Bhalerao, R., Casimiro, I., Eklof, J., Casero, P. J., Bennett, M., et al. (2002). AUX1 promotes lateral root formation by facilitating indole-3-acetic acid distribution between sink and source tissues in the Arabidopsis seedling. Plant Cell 14, 589-597. doi: 10.1105/tpc.010354

Marín-González, E., and Suárez-López, P. (2012). And yet it moves: cell-to-cell and long-distance signaling by plant microRNAs. Plant Sci. 196, 18-30. doi: 10.1016/j.plantsci.2012.07.009

Martin, A., Adam, H., Díaz-Mendoza, M., Zurczak, M., González-Schain, N. D., and Suárez-López, P. (2009). Graft-transmissible induction of potato tuberization by the microRNA miR172. Development 136, 2873-2881. doi: 10.1242/dev.031658

Masuda, S., Sakuta, C., and Satoh, S. (1999). cDNA cloning of a novel lectin-like xylem sap protein and its root-specific expression in cucumber. Plant Cell Physiol. 40, 1177-1181. doi: 10.1093/oxfordjournals.pcp. a029504

Mathieu, J., Warthmann, N., Küttner, F., and Schmid, M. (2007). Export of FT protein from phloem companion cells is sufficient for floral induction in Arabidopsis. Curr. Biol. 17, 1055-1060. doi: 10.1016/j.cub.2007. 05.009

Matsubayashi, Y. (2011). Post-translational modifications in secreted peptide hormones in plants. Plant Cell Physiol. 52, 5-13. doi: 10.1093/pcp/pcq169

Matsumoto-Kitano, M., Kusumoto, T., Tarkowski, P., Kinoshita-Tsujimura, K., Vaclavikova, K., Miyawaki, K., et al. (2008). Cytokinins are central regulators of cambial activity. Proc. Natl. Acad. Sci. U.S.A. 105, 20027-20031. doi: 10.1073/pnas.0805619105

Miller, G., Schlauch, K., Tam, R., Cortes, D., Torres, M. A., Shulaev, V., et al. (2009). The plant NADPH oxidase RBOHD mediates rapid systemic signaling in response to diverse stimuli. Sci. Signal. 2, ra45. doi: 10.1126/scisignal.2000448

Miyawaki, K., Matsumoto-Kitano, M., and Kakimoto, T. (2004). Expression of cytokinin biosynthetic isopentenyltransferase genes in Arabidopsis: tissue specificity and regulation by auxin, cytokinin, and nitrate. Plant J. 37, 128-138. doi: 10.1046/j.1365-313X.2003.01945.X

Molnar, A., Melnyk, C. W., Bassett, A., Hardcastle, T. J., Dunn, R., and Baulcombe, D. C. (2010). Small silencing RNAs in plants are mobile and direct epigenetic modification in recipient cells. Science 328, 872-875. doi: 10.1126/science. 1187959

Mortier, V., Den Herder, G., Whitford, R., Van De Velde, W., Rombauts, S., D'haeseleer, K., et al. (2010). CLE peptides control Medicago truncatula nodulation locally and systemically. Plant Physiol. 153, 222-237. doi: 10.1104/pp.110.153718

Mortier, V., Fenta, B. A., Martens, C., Rombauts, S., Holsters, M., Kunert, K., et al. (2011). Search for nodulation-related CLE genes in the genome of Glycine max. J. Exp. Bot. 62, 2571-2583. doi: 10.1093/jxb/erq426

Mousavi, S. A., Chauvin, A., Pascaud, F., Kellenberger, S., and Farmer, E. E. (2013). GLUTAMATE RECEPTOR-LIKE genes mediate leaf-to-leaf wound signalling. Nature 500, 422-426. doi: 10.1038/nature12478

Navarro, C., Abelenda, J. A., Cruz-Oró, E., Cuéllar, C. A., Tamaki, S., Silva, J., et al. (2011). Control of flowering and storage organ formation in potato by FLOWERING LOCUS T. Nature 478, 119-122. doi: 10.1038/nature10431

Nishimura, R., Hayashi, M., Wu, G. J., Kouchi, H., Imaizumi-Anraku, H., Murakami, Y., et al. (2002). HAR1 mediates systemic regulation of symbiotic organ development. Nature 420, 426-429. doi: 10.1038/nature01231

Niwa, M., Daimon, Y., Kurotani, K., Higo, A., Pruneda-Paz, J. L., Breton, G., et al. (2013). BRANCHED1 interacts with FLOWERING LOCUS T to repress the floral transition of the axillary meristems in Arabidopsis. Plant Cell 25, 1228-1242. doi: $10.1105 /$ tpc.112.109090
Nontachaiyapoom, S., Scott, P. T., Men, A. E., Kinkema, M., Schenk, P. M., and Gresshoff, P. M. (2007). Promoters of orthologous Glycine max and Lotus japonicus nodulation autoregulation genes interchangeably drive phloem-specific expression in transgenic plants. Mol. Plant Microbe Interact. 20, 769-780. doi: 10.1094/mpmi-20-7-0769

Notaguchi, M. (2015). Identification of phloem-mobile mRNA. J. Plant Res. 128, 27-35. doi: 10.1007/s10265-014-0675-6

Notaguchi, M., Abe, M., Kimura, T., Daimon, Y., Kobayashi, T., Yamaguchi, A., et al. (2008). Long-distance, graft-transmissible action of Arabidopsis FLOWERING LOCUS T protein to promote flowering. Plant Cell Physiol. 49, 1645-1658. doi: 10.1093/pcp/pcn154

Notaguchi, M., Higashiyama, T., and Suzuki, T. (2015). Identification of mRNAs that move over long distances using an RNA-Seq analysis of Arabidopsis/Nicotiana benthamiana heterografts. Plant Cell Physiol. 56, 311321. doi: $10.1093 / \mathrm{pcp} / \mathrm{pcu} 210$

Notaguchi, M., Wolf, S., and Lucas, W. J. (2012). Phloem-mobile Aux/IAA transcripts target to the root tip and modify root architecture. J. Integr. Plant Biol. 54, 760-772. doi: 10.1111/j.1744-7909.2012.01155.x

Ohyama, K., Ogawa, M., and Matsubayashi, Y. (2008). Identification of a biologically active, small, secreted peptide in Arabidopsis by in silico gene screening, followed by LC-MS-based structure analysis. Plant J. 55, 152-160. doi: 10.1111/j.1365-313X.2008.03464.x

Ohyama, K., Shinohara, H., Ogawa-Ohnishi, M., and Matsubayashi, Y. (2009). A glycopeptide regulating stem cell fate in Arabidopsis thaliana. Nat. Chem. Biol. 5, 578-580. doi: 10.1038/nchembio.182

Okamoto, S., and Kawaguchi, M. (2015). Shoot HAR1 mediates nitrate inhibition of nodulation in Lotus japonicus. Plant Signal. Behav. 10, e1000138.

Okamoto, S., Ohnishi, E., Sato, S., Takahashi, H., Nakazono, M., Tabata, S., et al. (2009). Nod factor/nitrate-induced CLE genes that drive HAR1mediated systemic regulation of nodulation. Plant Cell Physiol. 50, 67-77. doi: $10.1093 / \mathrm{pcp} / \mathrm{pcn} 194$

Okamoto, S., Shinohara, H., Mori, T., Matsubayashi, Y., and Kawaguchi, M. (2013). Root-derived CLE glycopeptides control nodulation by direct binding to HAR1 receptor kinase. Nat. Commun. 4, 2191. doi: 10.1038/ncomms3191

Oparka, K. J., and Turgeon, R. (1999). Sieve elements and companion cells-traffic control centers of the phloem. Plant Cell 11, 739-750.

Pant, B. D., Buhtz, A., Kehr, J., and Scheible, W. R. (2008). MicroRNA399 is a longdistance signal for the regulation of plant phosphate homeostasis. Plant J. 53, 731-738. doi: 10.1111/j.1365-313X.2007.03363.x

Rédei, G. P. (1975). Arabidopsis as a genetic tool. Annu. Rev. Genet. 9, 111-127. doi: 10.1146/annurev.ge.09.120175.000551

Reid, D. E., Ferguson, B. J., and Gresshoff, P. M. (2011). Inoculation- and nitrate-induced CLE peptides of soybean control NARK-dependent nodule formation. Mol. Plant Microbe Interact. 24, 606-618. doi: 10.1094/mpmi-0910-0207

Reid, D. E., Li, D., Ferguson, B. J., and Gresshoff, P. M. (2013). Structure-function analysis of the GmRIC1 signal peptide and CLE domain required for nodulation control in soybean. J. Exp. Bot. 64, 1575-1585. doi: 10.1093/jxb/ert008

Rep, M., Dekker, H. L., Vossen, J. H., De Boer, A. D., Houterman, P. M., De Koster, C. G., et al. (2003). A tomato xylem sap protein represents a new family of small cysteine-rich proteins with structural similarity to lipid transfer proteins. FEBS Lett. 534, 82-86. doi: 10.1016/S0014-5793(02)03788-2

Rep, M., Dekker, H. L., Vossen, J. H., De Boer, A. D., Houterman, P. M., Speijer, D., et al. (2002). Mass spectrometric identification of isoforms of PR proteins in xylem sap of fungus-infected tomato. Plant Physiol. 130, 904-917. doi: 10.1104/pp.007427

Roberts, I., Smith, S., De Rybel, B., Van Den Broeke, J., Smet, W., De Cokere, S., et al. (2013). The CEP family in land plants: evolutionary analyses, expression studies, and role in Arabidopsis shoot development. J. Exp. Bot. 64, 5371-5381. doi: 10.1093/jxb/ert331

Ruffel, S., Krouk, G., Ristova, D., Shasha, D., Birnbaum, K. D., and Coruzzi, G. M. (2011). Nitrogen economics of root foraging: transitive closure of the nitratecytokinin relay and distinct systemic signaling for $\mathrm{N}$ supply vs. demand. Proc. Natl. Acad. Sci. U.S.A. 108, 18524-18529. doi: 10.1073/pnas.1108684108

Sakakibara, H. (2006). Cytokinins: activity, biosynthesis, and translocation. Annu. Rev. Plant Biol. 57, 431-449. doi: 10.1146/annurev.arplant.57.032905.105231

Sakuta, C., Oda, A., Yamakawa, S., and Satoh, S. (1998). Root-specific expression of genes for novel glycine-rich proteins cloned by use of an antiserum 
against xylem sap proteins of cucumber. Plant Cell Physiol. 39, 1330-1336. doi: 10.1093/oxfordjournals.pcp.a029338

Sasaki, T., Chino, M., Hayashi, H., and Fujiwara, T. (1998). Detection of several mRNA species in rice phloem sap. Plant Cell Physiol. 39, 895-897. doi: 10.1093/oxfordjournals.pcp.a029451

Sasaki, T., Suzaki, T., Soyano, T., Kojima, M., Sakakibara, H., and Kawaguchi, M. (2014). Shoot-derived cytokinins systemically regulate root nodulation. Nat. Commun. 5, 4983. doi: 10.1038/ncomms5983

Satoh, S., Iizuka, C., Kikuchi, A., Nakamura, N., and Fujii, T. (1992). Proteins and Carbohydrates in Xylem Sap from Squash Root. Plant Cell Physiol. 33, 841-847.

Schnabel, E., Journet, E. P., De Carvalho-Niebel, F., Duc, G., and Frugoli, J. (2005). The Medicago truncatula SUNN gene encodes a CLV1-like leucine-rich repeat receptor kinase that regulates nodule number and root length. Plant Mol. Biol. 58, 809-822. doi: 10.1007/s11103-005-8102-y

Schuetz, M., Smith, R., and Ellis, B. (2013). Xylem tissue specification, patterning, and differentiation mechanisms. J. Exp. Bot. 64, 11-31. doi: 10.1093/jxb/ers287

Searle, I. R., Men, A. E., Laniya, T. S., Buzas, D. M., Iturbe-Ormaetxe, I., Carroll, B. J., et al. (2003). Long-distance signaling in nodulation directed by a CLAVATA1-like receptor kinase. Science 299, 109-112. doi: 10.1126/science.1077937

Seto, Y., Sado, A., Asami, K., Hanada, A., Umehara, M., Akiyama, K., et al. (2014). Carlactone is an endogenous biosynthetic precursor for strigolactones. Proc. Natl. Acad. Sci. U.S.A. 111, 1640-1645. doi: 10.1073/pnas.1314805111

Seto, Y., and Yamaguchi, S. (2014). Strigolactone biosynthesis and perception. Curr. Opin. Plant Biol. 21, 1-6. doi: 10.1016/j.pbi.2014.06.001

Soler, R., Erb, M., and Kaplan, I. (2013). Long distance root-shoot signalling in plant-insect community interactions. Trends Plant Sci. 18, 149-156. doi: 10.1016/j.tplants.2012.08.010

Stadler, R., Wright, K. M., Lauterbach, C., Amon, G., Gahrtz, M., Feuerstein, A., et al. (2005). Expression of GFP-fusions in Arabidopsis companion cells reveals non-specific protein trafficking into sieve elements and identifies a novel post-phloem domain in roots. Plant J. 41, 319-331. doi: 10.1111/j.1365313X.2004.02298.x

Tabata, R., Sumida, K., Yoshii, T., Ohyama, K., Shinohara, H., and Matsubayashi, Y. (2014). Perception of root-derived peptides by shoot LRR-RKs mediates systemic N-demand signaling. Science 346, 343-346. doi: 10.1126/science. 1257800

Takeda, R., Petrov, A. I., Leontis, N. B., and Ding, B. (2011). A three-dimensional RNA motif in Potato spindle tuber viroid mediates trafficking from palisade mesophyll to spongy mesophyll in Nicotiana benthamiana. Plant Cell 23, 258-272. doi: 10.1105/tpc.110.081414

Takei, K., Sakakibara, H., Taniguchi, M., and Sugiyama, T. (2001). Nitrogendependent accumulation of cytokinins in root and the translocation to leaf: implication of cytokinin species that induces gene expression of maize response regulator. Plant Cell Physiol. 42, 85-93. doi: 10.1093/pcp/pce009

Takei, K., Ueda, N., Aoki, K., Kuromori, T., Hirayama, T., Shinozaki, K., et al. (2004). AtIPT3 is a key determinant of nitrate-dependent cytokinin biosynthesis in Arabidopsis. Plant Cell Physiol. 45, 1053-1062. doi: 10.1093/pcp/pch119
Tamaki, S., Matsuo, S., Wong, H. L., Yokoi, S., and Shimamoto, K. (2007). Hd3a protein is a mobile flowering signal in rice. Science 316, 1033-1036. doi: $10.1126 /$ science. 1141753

Umehara, M., Hanada, A., Yoshida, S., Akiyama, K., Arite, T., Takeda-Kamiya, N., et al. (2008). Inhibition of shoot branching by new terpenoid plant hormones. Nature 455, 195-200. doi: 10.1038/nature07272

Vlot, A. C., Klessig, D. F., and Park, S. W. (2008). Systemic acquired resistance: the elusive signal(s). Curr. Opin. Plant Biol. 11, 436-442. doi: 10.1016/j.pbi.2008.05.003

Weller, J. L., Hecht, V., Liew, L. C., Sussmilch, F. C., Wenden, B., Knowles, C. L., et al. (2009). Update on the genetic control of flowering in garden pea. J. Exp. Bot. 60, 2493-2499. doi: 10.1093/jxb/erp120

Wigge, P. A., Kim, M. C., Jaeger, K. E., Busch, W., Schmid, M., Lohmann, J. U., et al. (2005). Integration of spatial and temporal information during floral induction in Arabidopsis. Science 309, 1056-1059. doi: 10.1126/science. 1114358

Xoconostle-Cázares, B., Xiang, Y., Ruiz-Medrano, R., Wang, H. L., Monzer, J., Yoo, B. C., et al. (1999). Plant paralog to viral movement protein that potentiates transport of mRNA into the phloem. Science 283, 94-98. doi: 10.1126/science.283.5398.94

Yano, M., Kojima, S., Takahashi, Y., Lin, H., and Sasaki, T. (2001). Genetic control of flowering time in rice, a short-day plant. Plant Physiol. 127, 1425-1429. doi: 10.1104/pp.010710

Yoo, B. C., Kragler, F., Varkonyi-Gasic, E., Haywood, V., Archer-Evans, S., Lee, Y. M., et al. (2004). A systemic small RNA signaling system in plants. Plant Cell 16, 1979-2000. doi: 10.1105/tpc.104.023614

Yoo, S. C., Chen, C., Rojas, M., Daimon, Y., Ham, B. K., Araki, T., et al. (2013). Phloem long-distance delivery of FLOWERING LOCUS T (FT) to the apex. Plant J. 75, 456-468. doi: 10.1111/tpj.12213

Zhang, K., Novak, O., Wei, Z., Gou, M., Zhang, X., Yu, Y., et al. (2014). Arabidopsis ABCG14 protein controls the acropetal translocation of root-synthesized cytokinins. Nat. Commun. 5, 3274. doi: 10.1038/ ncomms 4274

Zhang, S., Sun, L., and Kragler, F. (2009). The phloem-delivered RNA pool contains small noncoding RNAs and interferes with translation. Plant Physiol. 150, 378-387. doi: 10.1104/pp.108.134767

Conflict of Interest Statement: The authors declare that the research was conducted in the absence of any commercial or financial relationships that could be construed as a potential conflict of interest.

Copyright $\odot 2015$ Notaguchi and Okamoto. This is an open-access article distributed under the terms of the Creative Commons Attribution License (CC BY). The use, distribution or reproduction in other forums is permitted, provided the original author(s) or licensor are credited and that the original publication in this journal is cited, in accordance with accepted academic practice. No use, distribution or reproduction is permitted which does not comply with these terms. 